\title{
Earthwork laboratory tests and suction - experimental and numerical approach
}

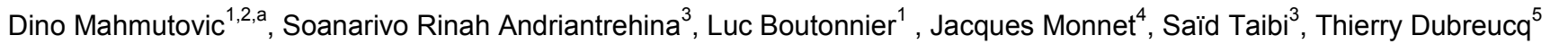 \\ Th \\ •

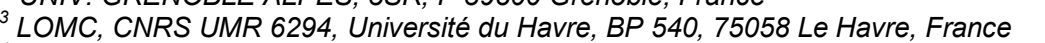

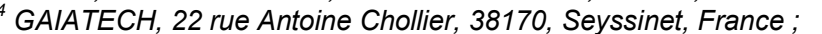

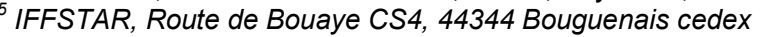

\begin{abstract}
The research presented in this publication is funded by the French National Project « Terredurable », which is dedicated to the study of soils in quasi-saturated conditions (close to saturation). Stability and deformation of earth structures are reanalyzed with a quasi-saturated hydromechanical model. In this paper, IPI tests are modeled with a two-dimensional explicit finite difference program (Flac 2D). The model presented considers mechanical soil theory to approach earthwork tests by integrating a compressible bulk modulus. Results of the numerical approach show how it is possible to link parameters of near saturation soil mechanic (saturation, suction) to earthwork strength of soil parameters (IPI value).
\end{abstract}

This communication is devoted to the simulation of IPI tests. In the first part, details about Proctor test and IPI tests will be given, with main experimental results. Then oedometric tests, suction measurement, triaxial tests, mercury porosimetry and grain density $\left(\gamma_{\mathrm{s}}\right)$ measurements have been performed on Proctor samples in order to feed our model to simulate soils near saturation. Finally simulations are carried out using FLAC to reproduce IPI settlement curves.

This paper aims at a better comprehension of IPI tests and the hydro-mechanical behavior related to those tests.

\section{Description of laboratory tests}

IPI laboratory tests (standard NF-EN-13286-47) are carried out in 8 samples from the same compacted soil with different water contents. Results of IPI test are represented in Figure 1. For a better comparison with the numerical results, the complete loading curve of the force applied on the soil with respect to the settlement is drawn. The elastic and the plastic part of the curve can so be appreciated.

The main characteristics of the studied soil are presented in Table 1 below.

Table 1. Main geotechnical characteristics of the studied soil, which come from A304 site (marl soil)

\begin{tabular}{|c|c|c|c|c|c|}
\hline $\begin{array}{c}\text { Type } \\
\text { of soil }\end{array}$ & $\begin{array}{c}\text { GTR } \\
\text { class }\end{array}$ & $\begin{array}{c}\% \\
\mathrm{CaCO}_{3}\end{array}$ & $\mathrm{w}_{\mathrm{L}}$ & IP & $\begin{array}{c}\% 80 \\
\mu \mathrm{m}\end{array}$ \\
\hline marle & $\mathrm{A} 4$ & 18,5 & 80 & 49 & 94 \\
\hline
\end{tabular}

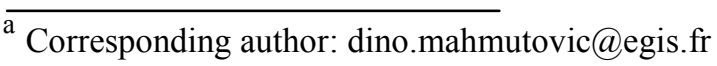

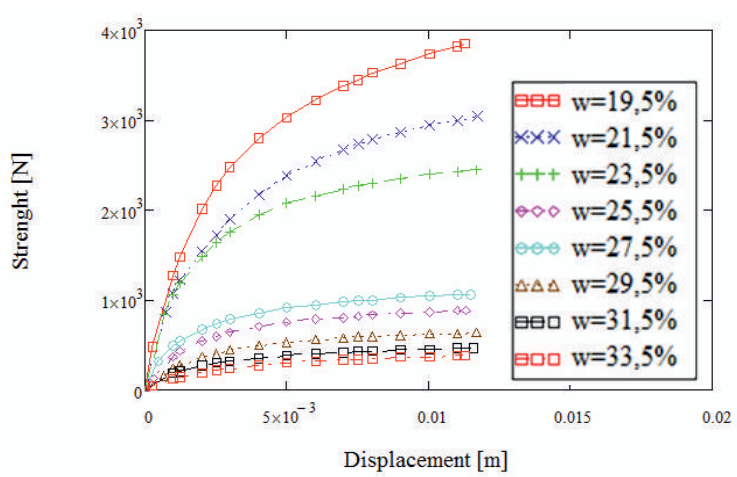

Figure 1. IPI experimental curves for different values of water content

In Figure 1, decrease of water content coincides with increase of reaction force. These obtained curves can be categorized into two groups: the first group with water content under $25.5 \%$ and the second group over this value. For the first group of curves, a high increase of the ground reaction force is observed for a small decrease of the water content. For the second group, the influence of water content on the reaction force is smaller.

This tendency can be also observed from other parameters, as suction. Proctor tests with suction measurements (measured with a filter paper method) are used. The initial suction and densities determined by Proctor tests (as shown in Figure 2) are then used for numerical simulation: 

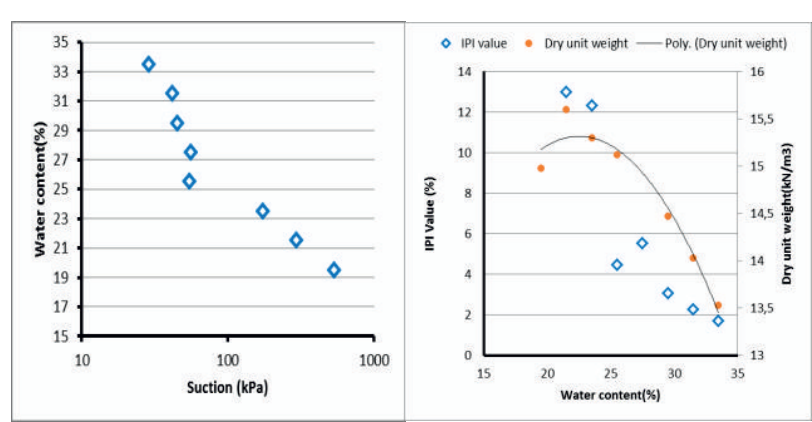

Figure 2. Evolution of suction and density as a function of water content

It can be found in Figure 2 that the suction values increase when the water content values decrease. These results show a change of slope between $23 \%$ and $25 \%$ of water content, which correspond the optimum Proctor water content. A same value can be also identified in the Figure 1. This value also represents the value of air entry (Boutonnier 2007).

Depending on if the water content locates at the dry or wet side (the air entry) of the Proctor curve, two different hydro-mechanical behaviours can be observed (Cui 1993).

In this paper only the wet side will be considered, since it concerns most earthworks, as illustrated in Figure 4. A theoretical model which is able to simulate the IPI tests will be introduced in the later section.

\section{Description of laboratory tests}

\subsection{Determination of the quasi-saturated parameters}

The model reported by Boutonnier theory (2007) is adopted in this work. Some details are available in papers of Mahmutovic et al. (2014), Boutonier et al. (2015), Andrianatrehina et al. (2015).

In this model, as shown in Figures 3 and 4, the soil can be divided into 4 domains of saturation (D1 to D4 unsaturated to saturated) (Boutonnier 2007).

A particular attention is paid to the transition zone from saturation to desaturation (domains D2 and D3)) which are the domain concerned by the IPI tests and earthworks (at optimum Proctor and on the wet side).

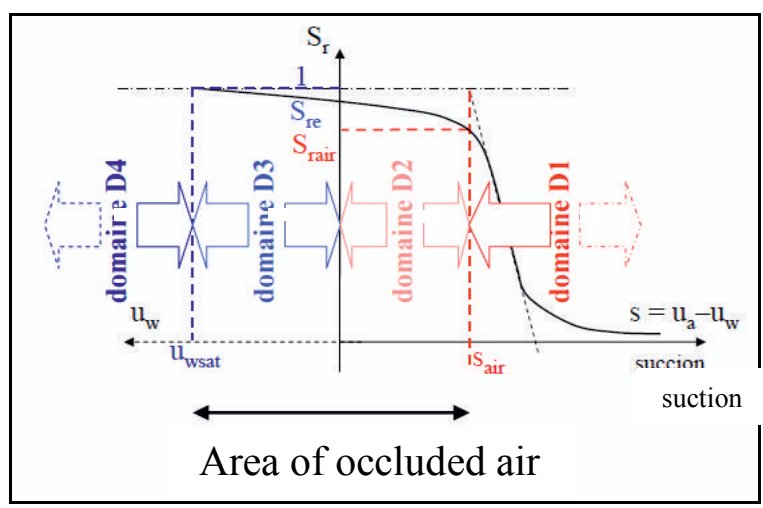

Figure 3. Division of retention curve in 4 domains of saturation

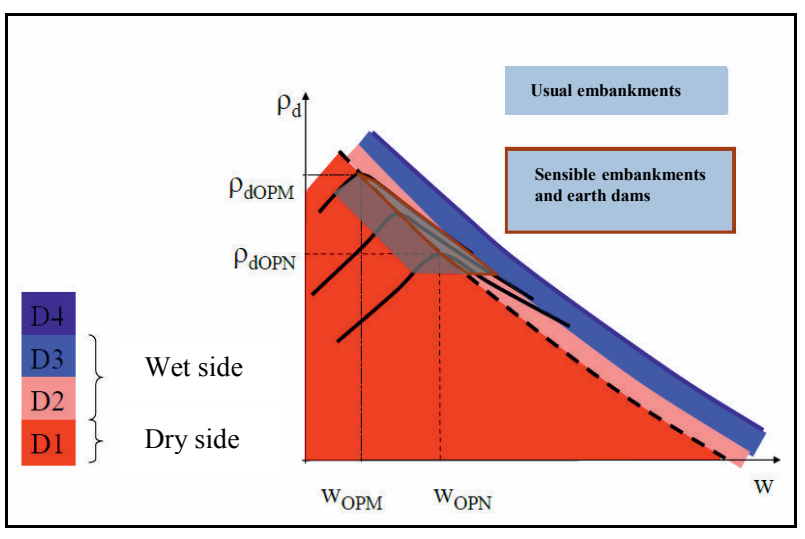

Figure 4. Division of Proctor curve in 4 domains of saturation

In the quasi-saturated areas, the model is based on the compressibility coefficient of the interstitial fluid $c_{f}$ (Equation for domain D2 (1) and Equation for domain D3 (2)) (Figures 3 and 4) which varies with the degree of water saturation in the soil.

$$
\begin{aligned}
\mathrm{c}_{\mathrm{f}} & =\frac{1}{\mathrm{~S}_{\mathrm{r}}} \cdot \frac{1}{S_{\text {air }}}\left(S_{r e}-S_{\text {rair }}\right)+c_{w} \\
\mathrm{c}_{\mathrm{f}} & =\frac{1-\mathrm{S}_{\mathrm{r}}+\mathrm{h} \cdot \mathrm{S}_{\mathrm{r}}}{u_{w}+r_{b m}+P_{a}-u_{w g}}+c_{w}
\end{aligned}
$$

This model contains 5 parameters: the degree of saturation for a null suction $\mathrm{S}_{\mathrm{re}}$, the degree of saturation at air entry $S_{\text {rair }}$, the air entry suction $S_{\text {air }}$, the mean radius of air bubbles $r_{b m}$, and the Henry's constant $h$.

The value of air entry suction coincides with the value of suction at the optimum Proctor $(200 \mathrm{kPa})$. With a measured value of $\gamma_{\mathrm{s}}$ of $27,5 \mathrm{kN} / \mathrm{m}^{3}$, a dry unit weight of $15,3 \mathrm{kN} / \mathrm{m}^{3}$, an optimum water content of $23 \%$, the value of saturation degree corresponding to the air entry (equation (3)) is $84,6 \%$.

$$
S_{\text {rair }}=\frac{\gamma_{S}}{\gamma_{W}} \frac{\gamma_{\text {dopt }} w_{\text {opt }}}{\gamma_{S}-\gamma_{\text {dopt }}}
$$

The degree of saturation for a null suction can be calculated for each sample (Table 2) if the suction and the degree of saturation have been tested at the beginning after the IPI test (equation (4)).

$$
S_{r}=S_{r e}-u_{w} \frac{\left(S_{\text {re }}-S_{\text {rair }}\right)}{u_{\text {wair }}}
$$

Table 2. Value of $S_{\text {re }}$ for different water content.

\begin{tabular}{|c|c|c|}
\hline $\begin{array}{c}\text { Water } \\
\text { content }\end{array}$ & $\mathbf{S}_{\mathbf{r e}}$ & $\mathbf{S}_{\text {re corrected }}$ \\
\hline $23,5 \%$ & 0,885 & 0,885 \\
\hline $25,5 \%$ & 0,919 & 0,920 \\
\hline $27,5 \%$ & 1,000 & 0,945 \\
\hline $29,5 \%$ & 0,968 & 0,965 \\
\hline $31,5 \%$ & 0,965 & 0,97 \\
\hline $33,5 \%$ & 0,940 & 0,975 \\
\hline
\end{tabular}


Two values of $S_{\text {re }}$ have been corrected in order to obtain a smooth curve. The mean radius of air bubbles obtained with Mercury porosimetry tests is close to $10^{-5} \mathrm{~m}$.

\subsection{Determination of the constitutive law parameters}

The quasi saturated parameters and the constitutive parameters have to be determined for the numerical simulation using modified Cam-Clay model. The parameters are the slope of the plastic loading $\lambda$ (Equation (5)), the slope of the elastic loading $\kappa$ (Equation (6)), the critical state line $\mathrm{M}$, the void ratio for the reference mean pressure of $1 \mathrm{kPa} \mathrm{N}_{0}$ (Equation (7)) and the mean pressure of preconsolidation $\mathrm{p}_{\mathrm{c}}$.

A consolidated and drained oedometric test allows the determination of $\lambda, \kappa$, and $\mathrm{N}_{0}$ parameters, as illustrated below (figure 5).

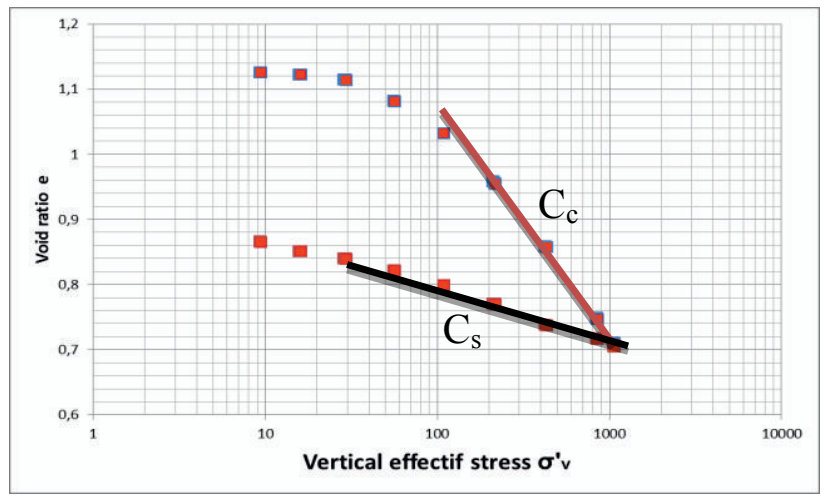

Figure 5. Oedometric curves for a sample taken from a soil compacted at the optimum Proctor and saturated before the test

$$
\begin{array}{r}
\lambda=\frac{c_{c}}{\ln 10} \\
\kappa=\frac{c_{s}}{\ln 10} \\
N_{0}=e+\lambda \ln \frac{p^{v}}{p^{v}{ }_{\text {ref } 1 k p a}}
\end{array}
$$

Three consolidated and drained triaxial tests are carried out (samples taken from a soil compacted at the optimum Proctor), under different consolidation pressures: 100 $\mathrm{kPa}, 200 \mathrm{kPa}$ and $500 \mathrm{kPa}$. The experimental results are represented below (Figure 6):

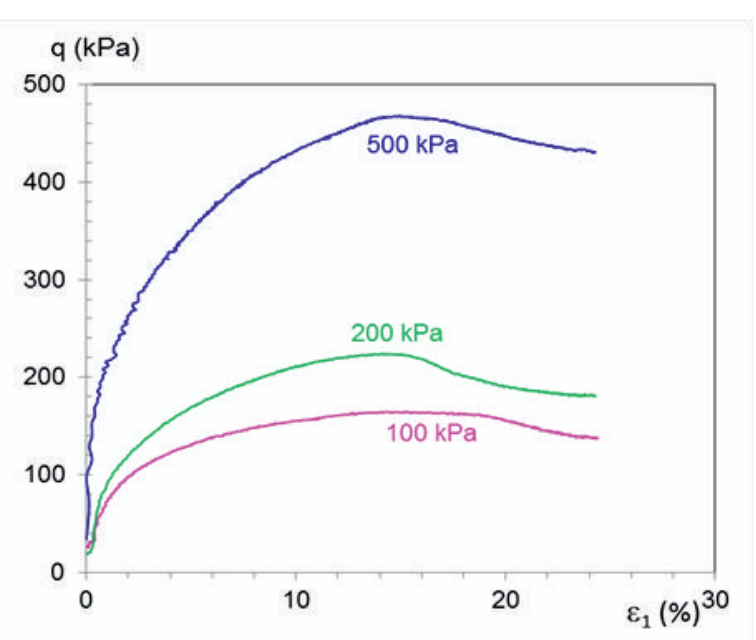

Figure 6. Shearing results of the triaxial $\mathrm{C}_{\mathrm{u}+\mathrm{u}}$ test on a sample taken from the soil compacted at the optimum Proctor

Figure 7 shows that the levels of pressure $100 \mathrm{kPa}$ and $200 \mathrm{kPa}$ are overconsolidated, whereas the $500 \mathrm{kPa}$ level is normally consolidated. The normally consolidated parameters will be used in the simulations with a value of $\mathrm{M}$ equal to 0.71 .

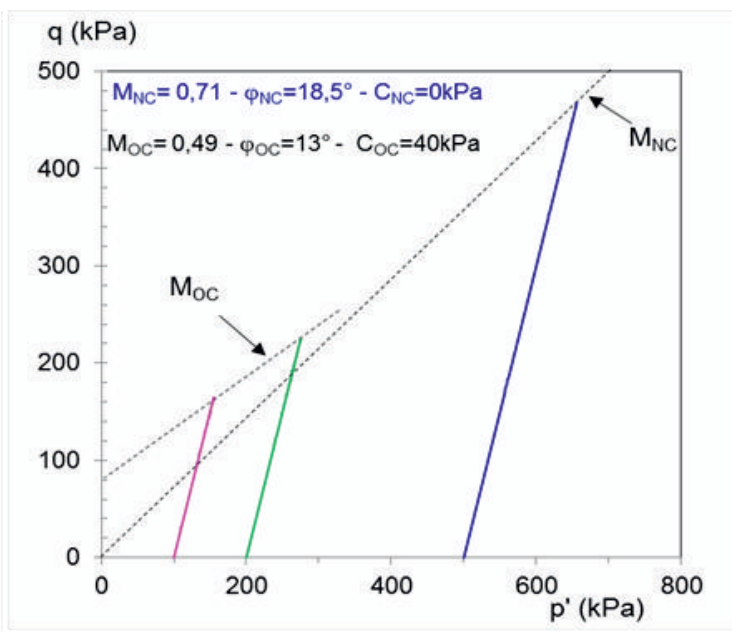

Figure 7. Limit shear strength for different lateral stress

The preconsolidation stress reflects the history of the ground in terms of stresses. Each Proctor test, compacted with a different water content, results from a different preconsolidation stress. These differences of values explain the variations observed in the IPI tests. The significance of the parameter $\mathrm{p}_{\mathrm{c}}$, will be discussed with the future simulations.

In a practical way, $\mathrm{p}_{\mathrm{c}}$ is the interception of the $\kappa$-slope and the $\lambda$-slope lines (Figure 8). If the initial state of stress of the soil at a given point in time is known as well as its void ratio, $\mathrm{p}_{\mathrm{c}}$ can be calculated using the virgin curve. This is where the Proctor tests and the suction measurements can step in. 


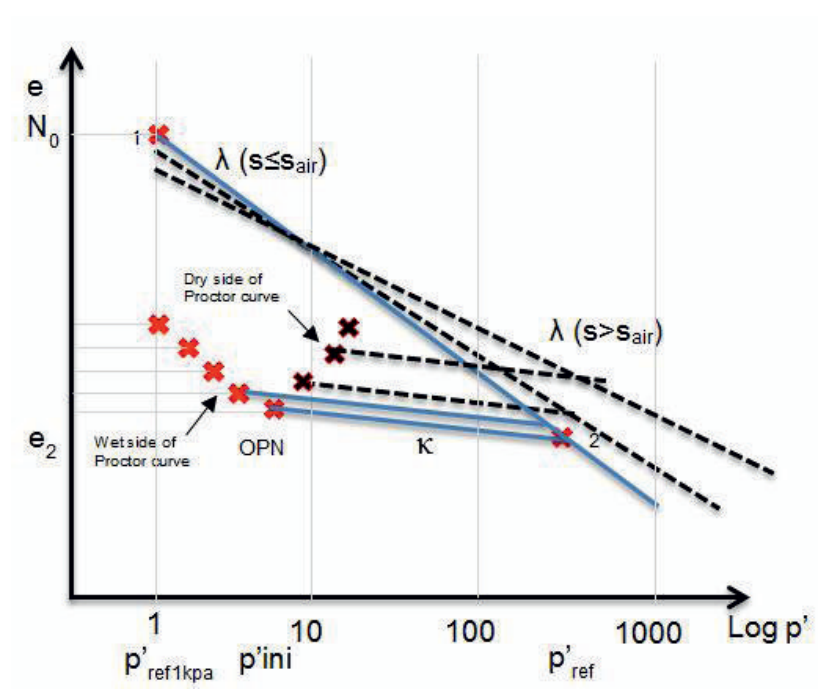

Figure 8. Evolution of the void ratio along the Proctor compaction.

$\gamma_{d}$ values determined through the Protor tests allow to calculate the initial void ratio before the IPI test, and the suction measurements allow to identify the initial vertical effective stress value (and the initial mean effective stress value afterwards). The value of the preconsolidated effective stress is given by the following formula (Eq. 8):

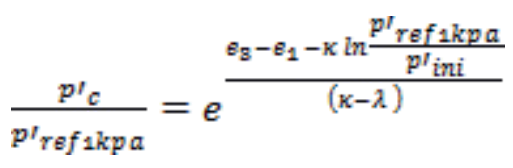

The value of the mean effective stress $\mathrm{p}^{\text {ini }}$ can be deduced from the vertical effective stress and the coefficient $\mathrm{K}_{0}$ (Equation (9)) with the following equation:

$$
p_{\text {ini }}^{\prime}=\frac{\sigma_{\text {vini }}+K_{0} \cdot \sigma_{\text {vini }}^{\prime}}{3}
$$

\subsection{Summary of parameters deduced from laboratory tests}

Parameters derived from laboratory tests are presented in the Table 3 and Table 4 below.

Table 3. Value of constitutive parameters for different values of

\begin{tabular}{|c|c|c|c|c|c|}
\hline $\mathbf{W}_{\text {nat }}$ & $\lambda$ & $\kappa$ & $\begin{array}{c}\mathbf{p}_{\mathrm{c}} \\
{[\mathrm{kPa}]}\end{array}$ & $\mathbf{M}$ & $\mathbf{N}_{\mathbf{0}}$ \\
\hline $25,5 \%$ & \multirow{5}{*}{0,153} & \multirow{5}{*}{0,04} & 1360 & \multirow{5}{*}{0,7} & \multirow{5}{*}{1,73} \\
\hline $27,5 \%$ & & & 975 & & \\
\hline $29,5 \%$ & & & 655 & & \\
\hline $31,5 \%$ & & & 369 & & \\
\hline $33,5 \%$ & & & 184 & & \\
\hline
\end{tabular}
water content
Table 4. Value of hydro-mechanical parameters for different values of water content

\begin{tabular}{|c|c|c|c|c|c|}
\hline $\mathbf{W}_{\text {nat }}$ & $\begin{array}{c}\text { Suction } \\
\mathbf{s}[\mathbf{k P a}]\end{array}$ & Dry density & $\begin{array}{c}\text { Void } \\
\text { ratio e }\end{array}$ & $\begin{array}{c}\mathbf{G s} \\
{[\mathbf{k N} /} \\
\left.\mathbf{m}^{\mathbf{3}}\right]\end{array}$ & $\mathbf{K}_{\mathbf{0}}$ \\
\hline $25,5 \%$ & 56 & 1,51 & 0,75 & & 1,75 \\
\hline $27,5 \%$ & 54 & 1,53 & 0,73 & & 1,55 \\
\hline $29,5 \%$ & 45 & 1,45 & 0,83 & \multirow{2}{*}{27,5} & 1,45 \\
\hline $31,5 \%$ & 42 & 1,40 & 0,89 & & 1,30 \\
\hline $33,5 \%$ & 29 & 1,35 & 0,96 & & 1,20 \\
\hline
\end{tabular}

K0 parameters are determined using Schmid (1966) relation (Equation (10)).

$$
K_{0}=(1-\sin \varphi)\left(\frac{\sigma_{v \max }^{\prime}}{\sigma_{v}^{\prime}}\right)^{0,5}
$$

\section{Description of the numerical simulation}

Flac software is used to implement the quasi saturated theory and simulate the IPI tests. Flac is based on a finite differences calculation code.

\subsection{Geometry and boundaries condition}

An axisymmetric calculation is used because of the axial symmetry of the IPI test. The geometry of the numerical model is drawn with the dimensions of $12 \mathrm{~cm}$ in height and $7,5 \mathrm{~cm}$ in radius which corresponds to the size of the CBR mould .

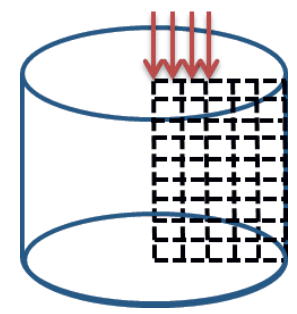

Figure 9. The illustration of the numerical simulation model

No displacement is allowed in $x-y$ directions at the base of the model and in $\mathrm{x}$ direction at the lateral boundary of the model. Large strain and a re-mesh of the grid are used during the simulation

\subsection{Stress fields initialisation}

The IPI test is performed after the Proctor test, thus after the compaction of the soil. The effect of this compaction has to be considered in the initialization of the stress field.

In order to implement this stress field, a silo type calculation was initially used considering the friction of the metallic mold with the soil. This calculation has been then simplified using a null friction as lubrication was used on the mold before compaction. 
Finally only weight of the soil and $\mathrm{K}_{0}$ coefficient are considered.

Suction is considered to be homogeneous inside each sample of soil (with different water content).The hypothesis is true only at the beginning of the IPI test (before the penetration of the piston).

\subsection{Use of a compressibility interstitial fluid}

The Equations (1) and (2) allow the use of a two phases model (soil and interstitial fluid) in our code. The value of the compressibility coefficient changes during the test with the value of the degree of saturation of water. The Terzaghi effective stress principle is used because the value of suction is under the air entry value.

\section{Results of the simulation and comparison with experimental results}

A numerical modeling is conducted for each Proctor test on the wet side of the optimum. The experimental Proctor values are then compared to those obtained by the proposed theoretical model, as shown in the Figures 10 . An accurate agreement is observed between experimental and theoretical models, which validates the proposed model. The same constitutive parameters have been used for all the simulations (with different water contents)
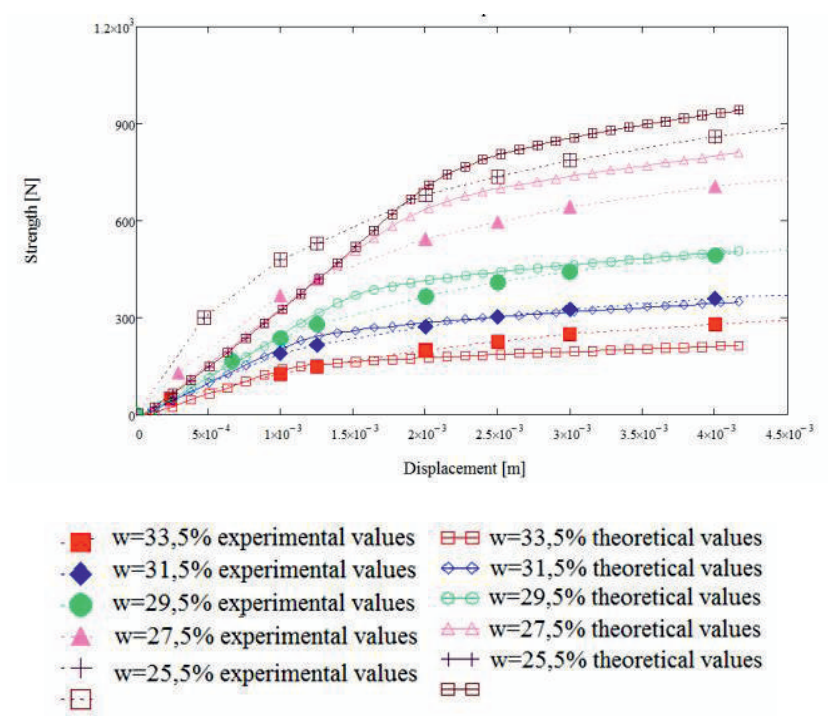

Figure 10. Comparison between experimental and numerical results of IPI test on the wet side of the Proctor curve.

The small discrepancies between numerical and experimental results may result from experimental uncertainties on the measure of suction and dry density of the soil. Influence of different parameters has been tested, including the suction, void ratio, compressibility coefficient.

Results of this parametric analysis are plotted in the Figures 11, 12 and 13.

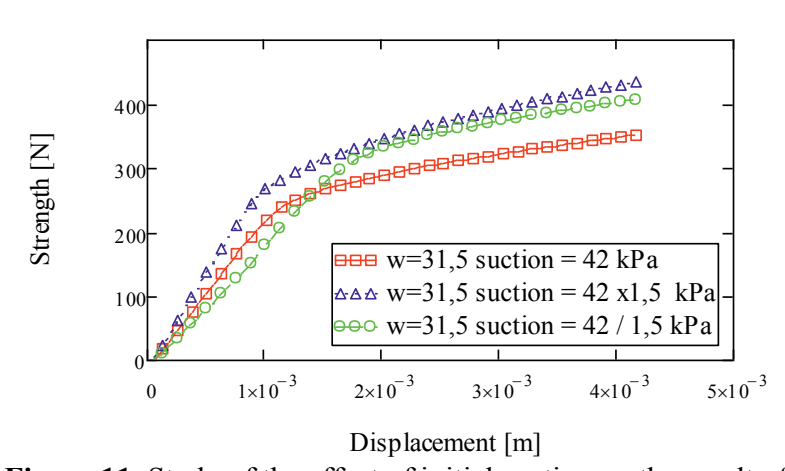

Figure 11. Study of the effect of initial suction on the result of reaction strength of soil for one example of IPI test $\left(\mathrm{W}_{\text {nat }}=\right.$ $31,5 \%)$

Figure 11 shows that the suction has a large influence in the initial slope of the curve and in the final value.

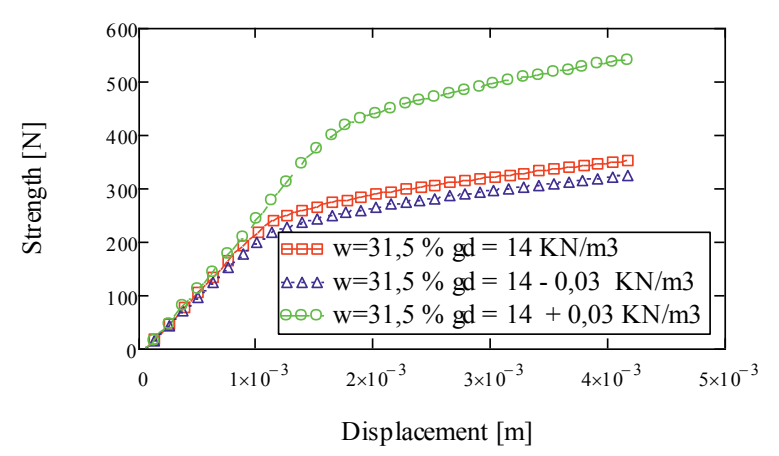

Figure 12 Study of the effect of initial void ratio on the result of reaction strength of soil for one example of IPI test $\left(\mathrm{W}_{\text {nat }}=31,5\right.$ $\%)$

Figure 12 shows that the lower is the void ratio (and the bigger is the dry unit weight), the bigger is reaction force of the soil. Figure 8 shows how the variation of the void ratio influences the value of preconsolidation pressure $\mathrm{p}_{\mathrm{c}}$.

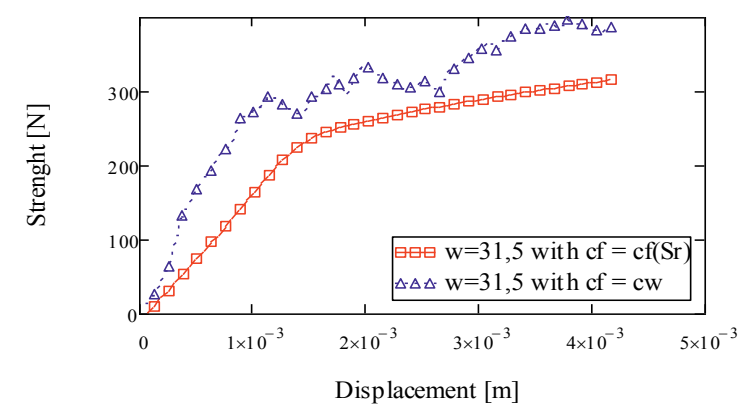

Figure 13. Study of the effect of compressibility coefficient $\left(c_{f}\right)$ for air/water phases on the result of reaction strength of soil for one example of IPI test $\left(\mathrm{W}_{\text {nat }}=31,5 \%\right)$

Figure 13 attest that the reaction force of the soil is strongly dependent of the value of the compressibility coefficient of interstitial fluid. 


\section{Conclusion}

IPI tests on marl have been presented. These tests are completed by, suction measurements, oedometric and triaxial tests. These different tests give us a better understanding of hydro-mechanical response of earthworks tests. A model of compressibility of the interstitial fluid has been validated on the wet side of the Proctor curve, as well as an elasto-plastic constitutive law of Cam-Clay type.

Based on the newly proposed model, it is found the reaction force of the soil during IPI test (on the wet side) is governed by 3 mains parameters: suction, preconsolidated effective stress, and compressibility coefficient $\left(\mathrm{c}_{\mathrm{f}}\right)$ for the air/water phases.

The next step will be numerical simulation of IPI test on the dry side of the Proctor curve. This work will take into account an extension of effective stress principle which depends on suction and the $\chi$ coefficient (Khalili et Khabbaz, 1998).

\section{Acknowledgment}

The authors would like to thank the French ANR project TerreDurable (ANR 2011 VILD 00401 convention, programme Bâtiments et villes durables), which permit the study of soils near to saturation and the provision of their laboratory test.

\section{References}

1. $\square$ Afnor 2005, norme NF-EN-13286-47, « Méthodes d'essai pour la détermination de l'indice portant Californien (CBR), de l'indice de portance immédiat (IPI) et du gonflement ».

2. $\square$ Andrianatrehina R., Mahmutovic, D., Boutonnier, L. taibi, S. Fleureau, J-M., Fry, J-J., Monnet, J. (2015). Observation of craking evolution during free dessication - experimental and numerical approaches. Symposium international SEC 2015. Marne-la-vallée.

3. $\square$ Boutonnier, L., Mahmutovic, D., Fry, J-J. (2015). Génération de pression interstitielle dans les fondations argileuses des barrages en remblai. Colloque CBR 2015.

4. $\square$ Boutonnier, L (2007 Comportement hydromécanique des sols fins proches de la saturation: cas des ouvrages en terre : coefficient $\mathrm{B}$, déformations instantanées et différées, retrait / gonflement. thèse INP Grenoble.

5. $\square$ Khalili, N., Khabbaz, M.H, (1998). A unique relationship for the shear strength of unsaturated soils. Geotechnique vol 48, n5, p.681-687.

6. $\square$ Mahmutovic, D., Monnet, J., Loret, B., Ple, O., Pelizzari, B., Boutonnier L., Lai B. (2014). A model for weakly unsaturated soils taking into account the three phases (air, water and soil). Unsat 2014. Sydney.

7. $\square$ Schmidt B., (1966), Discussion of "Earth pressures at rest related to stress history", Canadian Geotechnical Journal, vol. 3,4, pp.239-242. 